\title{
Effects of collaborative recall: denying true information is as powerful as suggesting misinformation
}

Citation for published version (APA):

Merckelbach, H. L. G. J., van Roermund, H., \& Candel, I. E. L. (2007). Effects of collaborative recall: denying true information is as powerful as suggesting misinformation. Psychology Crime \& Law, 13(6), 573-581. https://doi.org/10.1080/10683160601160679

Document status and date:

Published: 01/01/2007

DOI:

10.1080/10683160601160679

Document Version:

Publisher's PDF, also known as Version of record

Please check the document version of this publication:

- A submitted manuscript is the version of the article upon submission and before peer-review. There can be important differences between the submitted version and the official published version of record.

People interested in the research are advised to contact the author for the final version of the publication, or visit the DOI to the publisher's website.

- The final author version and the galley proof are versions of the publication after peer review.

- The final published version features the final layout of the paper including the volume, issue and page numbers.

Link to publication

\footnotetext{
General rights rights.

- You may freely distribute the URL identifying the publication in the public portal. please follow below link for the End User Agreement:

www.umlib.nl/taverne-license

Take down policy

If you believe that this document breaches copyright please contact us at:

repository@maastrichtuniversity.nl

providing details and we will investigate your claim.
}

Copyright and moral rights for the publications made accessible in the public portal are retained by the authors and/or other copyright owners and it is a condition of accessing publications that users recognise and abide by the legal requirements associated with these

- Users may download and print one copy of any publication from the public portal for the purpose of private study or research.

- You may not further distribute the material or use it for any profit-making activity or commercial gain

If the publication is distributed under the terms of Article 25fa of the Dutch Copyright Act, indicated by the "Taverne" license above, 


\title{
Effects of collaborative recall: Denying true information is as powerful as suggesting misinformation
}

\author{
HARALD MERCKELBACH, HUGO VAN ROERMUND, \& \\ INGRID CANDEL
}

Department of Experimental Psychology, Maastricht University, Maastricht, The Netherlands

(Received 14 August 2006; revised 3 November 2006; accepted 8 December 2006)

\begin{abstract}
Using a social contagion paradigm, we compared the corruptive effects on memory of two types of post-event misinformation: Suggesting incorrect details and denying correct details. Together with a confederate, undergraduate participants $(n=90)$ watched complex scenes. Next, participant and confederate took turns in recalling scene details. In one condition, the confederate suggested incorrect details, whereas in the other condition the confederate denied true details recalled by the participant. Finally, participants were given a second free recall test in the absence of the confederate. Denying correct details appeared to be as powerful as suggesting incorrect information, with $72 \%$ of the participants omitting previously mentioned, but confederate-denied, details from their free recalls and $52 \%$ incorporating incorrect details in their free recall. Also, these participants scored higher on the Gudjonsson Compliance Scale than those who were not misled by the suggestions of the confederate.
\end{abstract}

Keywords: Memory conformity effects, social contagion paradigm, collaborative recall, Gudjonsson Compliance Scale

\section{Introduction}

Recall of memories is not a purely individual phenomenon, particularly not in the forensic context. For example, before they are formally interviewed by the police, eyewitnesses often discuss with one another the details of the incident they saw (Paterson \& Kemp, 2005). Wagenaar and Crombag (2005) used the term collaborative storytelling to refer to situations in which eyewitnesses talk to each other to make sense of what has happened and by doing so, influence each other's accounts. These authors presented a legal case illustrating the co-construction of eyewitness memories, one important element of which is the exchange of post hoc misinformation.

A laboratory analogue of this co-construction of memories is provided by Roediger, Meade, and Bergman's (2001) social contagion paradigm. In this paradigm, participants and a confederate together see scenes and then engage in a collaborative recall session in which the confederate comes up with details that were not part of the scenes. Finally, the participant is given an individual recall test. What is typically found is that during this final

Correspondence: Harald Merckelbach, Faculty of Psychology, Department of Experimental Psychology, Maastricht University, PO Box 616, 6200 MD Maastricht, The Netherlands 
recall test, participants often reproduce the erroneous details (Roediger et al., 2001). This social contagion effect becomes more pronounced when the erroneous details are plausible and participants' exposure to scenes have been relatively brief (Roediger et al., 2001) or participants think that it was (too) brief (Gabbert, Memon, \& Wright, 2007). There is also strong evidence that misinformation transmitted along social routes (e.g. overhearing another individual recalling erroneous details) is more influential in corrupting memory reports than misinformation from a non-social source (e.g. misinformation in the form of, for example, written narratives; Gabbert, Memon, Allan, \& Wright, 2004).

So far, research on misinformation effects has primarily focused on participants or eyewitnesses adding erroneous details to their memory reports (i.e. commission errors). Much less is known about misinformation that takes the form of rejecting correct details previously reported by the eyewitness or participant. Does this type of misinformation promote omission errors? That is, does it discourage people from reporting details that they previously did report? This is not only a theoretically interesting issue, but it also bears relevance to forensic issues. For example, referring to the recovered memory debate, Conte (1999; p. 86) wrote: "A potential area of investigation that may further our understanding of trauma and memory would be whether or not it is possible to get an individual who actually had an experience to report that he or she did not have that experience."

As a matter of fact, a handful of recent studies have looked at whether misinformation might lead participants to omit correct details from their memory reports. In one study, Wright, Loftus, and Hall (2001) showed their participants a scene of a restaurant (experiment 1) or a clip of a drunk-driving incident (experiment 2) and then they were asked to retell or imagine the event on the basis of cue descriptions to which incorrect details were added or from which correct details were omitted. Finally, recall tests were given. The authors found that omitting critical details from the cues subsequently made participants less likely to report these details. Wright and co-workers also noted that the magnitude of this omission effect was similar to that of misinformation intending to add incorrect details to participants' reports. However, Gabbert, Memon, and Wright (2006; experiment 2) reached a different conclusion. Rather than using a non-social means of presenting misinformation, these authors created a situation in which social exchange of misinformation occurred. More specifically, they had participants watch different versions of a film clip such that details of the same scene were added or omitted. Participants were led to believe that they had seen the same clip. Next, the researchers had pairs of participants engage in collaborative recall and finally gave them an individual free recall test. The authors found that individuals were more likely to add a detail to their free recall when it had been introduced by their partner during a previous collaborative recall session than to omit a detail from their free recall when it had been rejected by their partner during collaborative recall. This would suggest that it is easier to "implant" than to "remove" a memory (see for similar conclusion, Wright, Mathews, \& Skagerberg, 2005).

In the current study, we used a version of Roediger et al.'s (2001) social contagion paradigm to examine the effects of two different types of post-event misinformation: Misinformation that adds incorrect details versus misinformation that denies correct details. Given the mixed results of earlier studies, we were especially interested in the magnitude of both effects: Is it easier to have people add an incorrect detail to their memory report than to discourage them from reporting a correct detail (e.g. Gabbert et al., 2006)? Or are these two effects comparable in terms of their strength (Wright et al., 2001)? Based on Loftus, Levidow, and Duensing (1992) discrepancy detection principle, we expected that it is more difficult "to remove" a correct detail than "to implant" an incorrect detail 
since the former requires misinformation that clearly contradicts recollections, while the latter can be done with misinformation that is in principle consistent with existing recollections.

A subsidiary aim of our study was to explore whether participants who are sensitive to misinformation during collaborative recall score higher on an instrument measuring eagerness to please compared to those who are not. If so, this could shed more light on how the social exchange of memories might subsequently affect the free recall of individuals who in social isolation try to reconstruct what they have seen. With this in mind, we had participants complete the Gudjonsson Compliance Scale (GCS; Gudjonsson, 1989), which is a forensic tool for measuring eagerness to please (i.e. compliance). For example, studies by Gudjonsson and co-workers (e.g. Sigurdsson \& Gudjonsson, 1996) have noted that prison inmates who claim to have falsely confessed score higher on the GCS than inmates without such claim. This suggests that the tendency to reproduce misinformation offered by others is associated with heightened GCS scores.

\section{Method}

\section{Participants}

The sample consisted of 90 undergraduate psychology students (60 women) at Maastricht University, who received either course credits or $€ 7.50$ for their participation. Their mean age was 20 years $(S D=1.78$ years). The study was approved by the standing ethical committee of the Faculty of Psychology.

\section{Materials}

Together with a confederate, each participant looked at six pictures presented on a 19-inch computer screen. The pictures depicted a desk (see example, Figure 1), a kitchen, a

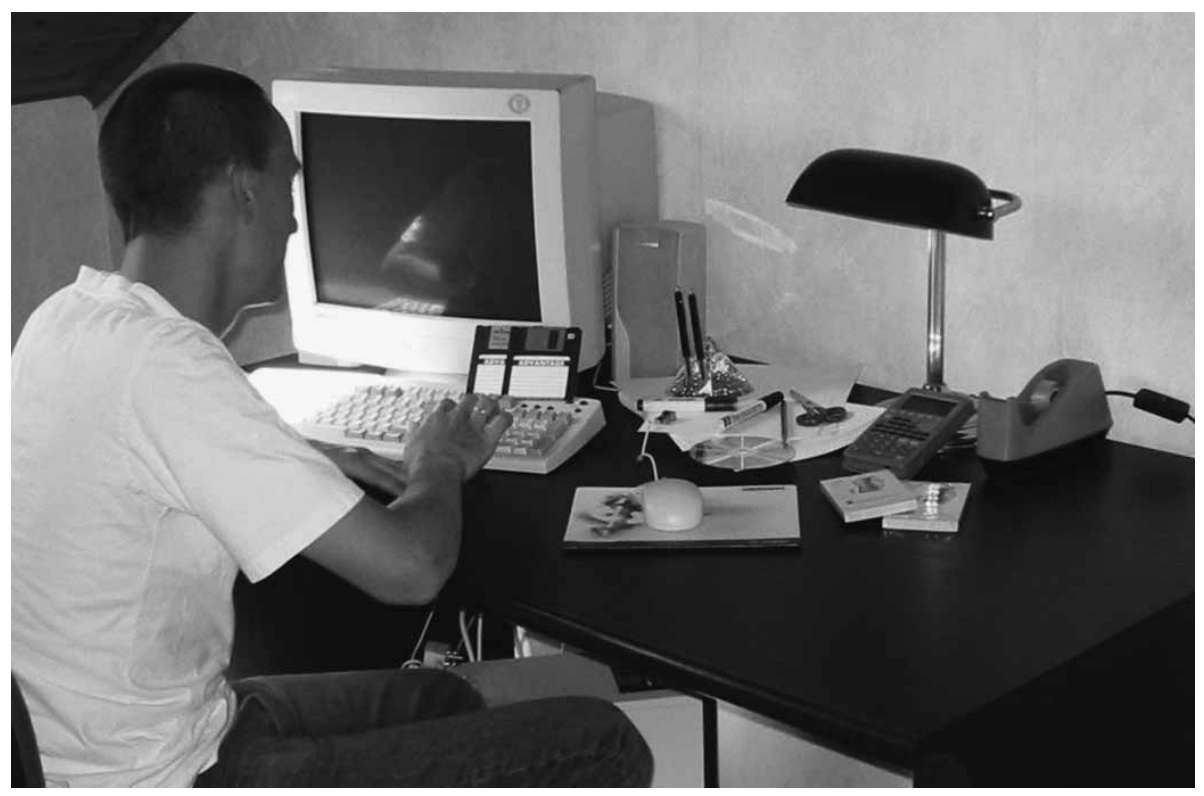

Figure 1. Example of scene (“desk”). 
bedroom, a bathroom, a closet, and a garage. Each scene was presented for 15 seconds and was preceded by a title slide (e.g. "desk"). Scenes contained on average 20 clearly recognizable details.

Participants completed the Gudjonsson Compliance Scale (GCS; Gudjonsson, 1989; Cronbach's alpha $=0.72$ ), which is a measure of the tendency to comply with social demands. The GCS is a self-report consisting of 20 true/false statements that have to do with how individuals deal with conflicts and confrontation (e.g. "I give in easily to people when I'm pressured"). Responses are summed to obtain a total score, with higher scores reflecting a stronger tendency to comply.

\section{Procedure}

Participants were instructed to look carefully at each picture and were told that a memory test would be given. The order of the pictures was counterbalanced across the conditions (see below). After they had seen the six pictures, participants and confederate were given a 4-minute filler task that consisted of arithmetic problems (e.g. additions and subtractions). They were instructed to solve as many problems as possible. Following this, collaborative recall began such that participant and confederate took turns in recalling items from each scene. Thus, the participant started by mentioning one item, followed by the confederate mentioning a different item, until both had recalled six items for a given scene. Collaborative recall was structured by presenting on the computer screen the titles of the pictures in the correct order. After each title appeared, the experimenter asked "What do you remember of this picture?" while carefully controlling the turns of participant and confederate. There were three conditions: In the control condition, the confederate came up with six correct details not mentioned earlier by the participant. The reason for including an active, but non-manipulating confederate in this condition is that we wanted to create an adequate baseline for testing misinformation manipulations by confederates (see below) rather than controlling for the mere presence of confederates. In the add condition, the confederate produced during his final turns for the third and sixth picture a commission error by mentioning a plausible detail that had not been present in the scenes (e.g. "a telephone" in the case of the desk scene). The details came from a pool of high-expectancy (cf. Roediger et al., 2001), but erroneous details suggested by a panel of pilot participants $(n=10)$. In this pilot study, participants watched the slides and for each, they were instructed to come up with details that were not part of the scene, but would have perfectly matched with the gist of the scene. We selected those erroneous details that were mentioned by a majority of the pilot participants.

In the deny condition, the confederate disputed the sixth item mentioned by the participant for the third and the sixth picture. Thus, the confederate remarked in a confident tone that "the detail that you mention was certainly not present in this picture; otherwise I would have noticed that." The experimenter acted in such way that no further discussion could ensue between participant and confederate. Of course, items disputed by the confederate varied because participants mentioned different items in the sixth position. However, as on average slides contained 20 clearly recognizable details, there is every reason to assume that the details that participants mentioned in the sixth position were not the ones they were unsure about (cf. the output order effect described by Schwartz, Fisher, \& Hebert, 1998).

There were two confederates: one male and one female undergraduate. Both were trained to reproduce all items from each picture. Within each condition, half of the participants were confronted with the male confederate, while the other half was confronted with the 
female confederate. The three conditions did not differ with regard to the number of female participants $\left[\chi^{2}(2)<1.0, \mathrm{NS}\right]$.

After the collaborative recall, participants and confederates were escorted to separate testing rooms. From here on, participants were tested individually. They first had to complete a second arithmetic filler task that lasted for 10 minutes. Next, they were given a free recall which was structured as follows: Participants were shown the title of a picture and then had 2 minutes to write down all the items they remembered from the picture. Titles were presented in the same order in which participants had seen the pictures. Finally, participants completed the GCS.

\section{Analyses}

Given the nature of the stimulus material (i.e. distinct items rather than narratives), coding of free recall protocols did not pose any interpretational problems. Having coded free recalls, we compared the number of participants in the add and the deny conditions, who accepted the misinformation provided by the confederate to baseline frequencies in the control condition. That is, we counted the number of participants who during individual free recall reproduced at least one of the two commission errors of the confederate (add condition) or avoided at least one of the two correct details previously mentioned by themselves, but rejected by the confederate (deny condition). Using Chi-square tests, these data were compared with the number of control participants who spontaneously free recalled the commission error or spontaneously avoided the sixth detail that they had previously mentioned for the third and sixth scene. Using $t$-tests, we also investigated whether persons who deferred to the confederates by either reproducing false details or omitting correct details scored higher on the GCS relative to those who did not accept the confederate's misinformation.

\section{Results}

Table I gives the mean number of correct free recall items and mean GCS scores of control participants, participants in the add condition, and participants in the deny condition. The overall mean GCS score was $8.6(\mathrm{SD}=3.7$; range: $0-18)$, which is fairly typical for student samples (e.g. Gudjonsson, Sigurdsson, Bragason, Einarsson, \& Valdimarsdottir, 2004). Participants in the three conditions did not differ with regard to their mean GCS scores $[F(2,87)=1.81, p=0.16]$. Neither did they differ with respect to their correct free recall levels $[F(2,87)<1.0, \mathrm{NS}]$. The male and female confederate did not differ in their efficiency to elicit reproduction of false details or denial of correct details during free recall $\left[\chi^{2}(1)<1.0, \mathrm{NS}\right]$.

Table I. Mean correct free recall items averaged over six pictures (and SD), GCS scores (and SD), and absolute frequencies (and percentages) of participants who produced commission errors and avoided correct items during free recall for the control condition, the add condition, and the deny condition.

\begin{tabular}{lccc}
\hline & $\begin{array}{c}\text { Control } \\
(n=30)\end{array}$ & $\begin{array}{c}\text { Add } \\
(n=31)\end{array}$ & $\begin{array}{c}\text { Deny } \\
(n=29)\end{array}$ \\
\hline Correct free recall & $7.6(1.7)$ & $7.6(1.6)$ & $7.7(1.3)$ \\
GCS & $7.7(3.6)$ & $8.3(4.0)$ & $9.5(3.5)$ \\
Produced incorrect details (\%) & $0(0)$ & $16(52)$ & $0(0)$ \\
Avoided correct details (\%) & $10(33)$ & $6(19)$ & $21(72)$ \\
\hline
\end{tabular}


Table I also shows to what extent participants in the add and deny conditions accepted the misinformation provided by the confederate. As can be seen, 16 out of 31 (52\%) participants in the add condition produced during individual free recall at least one of the two errant items earlier mentioned by the confederate. In contrast, none of the control participants spontaneously produced at least one of the high-expectancy commission errors, a difference that was significant: $\chi^{2}(1)=20.99, p<0.001$. Likewise, 21 out of $29(72 \%)$ participants in the deny condition failed to mention a correct item that they earlier did mention during collaborative recall, but that had been disputed by the confederate. Meanwhile, only 10 out of 30 control participants (33\%) spontaneously forgot to mention during individual free recall at least one the two correct items on the sixth position for the third and sixth scene that they did recall earlier. Again, this difference was significant: $\chi^{2}(1)=9.03, p=0.003$. To compare the corruptive effects on individual free recall of suggesting errant details versus denying correct details, we corrected the percentage of compliant participants in the deny condition (i.e. $72 \%$ ) for the baseline frequency of forgetting in the control condition (i.e. 33\%). Next, a chi-square test was conducted, which indicated that add and deny manipulations were similarly powerful: $\chi^{2}(1)=1.13, p=0.24$.

We next pooled participants in the add and deny conditions who apparently had accepted the misinformation presented during collaborative recall $(n=37)$ and compared their mean GCS score to that of participants who had not accepted the misinformation $(n=23)$. Participants who had come to adopt the misinformation scored significantly higher on the GCS than individuals who had not $[t(58)=2.39, p=0.020]$, means being $9.78(\mathrm{SD}=3.80)$ and $7.47(\mathrm{SD}=3.32)$, respectively. In terms of Cohen's $d$, this was a medium sized effect $[d=0.63]^{1}$

\section{Discussion}

The findings of the current study can be catalogued as follows. To begin with, replicating the standard social contagion effect described by Roediger et al. (2001), we found a considerable proportion of participants incorporating in their individual free recall erroneous details presented earlier by a confederate during collaborative recall. This standard effect can be seen as the social version of the typical post-event misinformation phenomenon in which individuals add errant memory details to their reports on the basis of what they have heard or seen some time after exposure to the critical scene (Gabbert et al., 2004, 2007). The psycholegal relevance of this phenomenon is obvious. After all, eyewitnesses often talk with one another about the meaning of what they have seen and this creates ample opportunities for the standard social contagion effect. Thus, there is the risk that what appears in court as independent accounts of multiple eyewitnesses is, in fact, the erroneous echo of a single individual. The implication would be that triers of fact are well-advised to investigate carefully to what extent eyewitnesses have engaged in pretrial conversational remembering (Wagenaar \& Crombag, 2005).

Secondly, we found that misinformation taking the form of denying correct memory details is also able to corrupt memory reports in the sense that participants exposed to such misinformation subsequently avoid mentioning these details during an individual free recall. Thus, our results concur with those of Wright et al. (2001) and Gabbert et al. (2006), who also found that this type of misinformation may "erase" details from memory reports. Of course, we do not know whether these details are really erased from memory or whether participants are so unsure about them that they are very reluctant to report such details. From a psycholegal perspective, the difference is not very relevant. What counts is 
that even when alone and not under immediate social pressure, the person avoids mentioning a detail that he or she previously did mention, but that was disputed by someone else. As to the size of this effect, our results fit nicely with those of Wright et al. (2001). These authors concluded that as far as free recall of details is concerned, suggesting erroneous details and denying correct details seem to possess a similar memory-corrupting potential. It is true that discrepancy detection (Loftus et al., 1992) must be easier for misinformation that denies correct details than for misinformation that suggests incorrect details. Yet, as our data as well as those of Wright et al. (2001) show, this does not necessarily imply that memory reports about event details are less likely to be influenced by the former than by the latter type of misinformation. It remains to be seen, however, whether denying correct information during collaborative recall is able to "erase" the report of a complete event. Several false memory studies have documented that by repeatedly providing participants with erroneous feedback, it is possible to create memories of events that never happened. Telling examples of this are provided by the lost-in-a-shopping-mall study of Loftus and Pickrell (1995) and the spilling-a-punch-bowl-on-the-parents-of-thebride study of Hyman, Husband, and Billings (1995). We do not know whether the opposite phenomenon can be documented as easily. That is, can misinformation denying an event lead participants to report that they did not experience that event when, in fact, they did? Pursuing this issue is important, because it might shed light on cases in which victims or perpetrators claim to be amnesic for a criminal event (e.g. sexual abuse, murder; Christianson \& Merckelbach, 2004). One distinct possibility is that in such cases, victims or perpetrators do not suffer from amnesia in the neurological sense of the word (i.e. inaccessibility of memory due to brain lesions), but from memory distrust brought about by social misinformation denying the criminal event.

A third and final finding of the current study is that those who accepted the suggestions of the confederate, by either adopting erroneous details or dropping correct details, had higher scores on the GCS (Gudjonsson, 1989) than those who did not. Previous work has related heightened scores on the GCS to suspects' tendency to falsely confess to a crime under interrogative pressure (e.g. Sigurdsson \& Gudjonsson, 1996). In the false confession literature, authors (e.g. Henkel \& Coffman, 2004) often make a distinction between individuals who falsely confess, but know full well that they are innocent (i.e. coerced compliant confessions) and individuals who falsely confess and come to believe that they are guilty (i.e. internalized false confessions). It is often assumed that social pressure underlies the first type of false confession, while a combination of social pressure and internal cognitive vulnerabilities (e.g. source monitoring difficulties) underlies the second type. However, the demarcation between the two types of false confession may not be that strict (e.g. Horselenberg et al., 2006). That is also the way in which we interpret the current findings: The collaborative recall in our study was a social process in which subtle pressure to accept misinformation occurred. During subsequent individual free recall, social pressure was absent when participants wrote their free recall items down, which allowed for a high degree of discretion. Nevertheless, the subtle social pressure created during collaborative recall had its corruptive effects on individual free recall and the higher participants scored on questions tapping avoidance of conflict and eagerness to please (i.e. the GCS items), the more pronounced these corruptive effects were. Apparently, social pressure factors have carry-over effects to cognitive processes involved in discrete free recall. We suspect that such carry-over effects are mediated by a phenomenon that has been termed memory distrust (Gudjonsson, 2003). That is to say, subtle social pressure may 
create a situation in which people come to mistrust their own memory and this may manifest itself during subsequent free recall.

One limitation of the current study is that it relied on a homogeneous sample of intelligent and healthy undergraduates. One could argue that in a heterogeneous community sample, the memory-undermining effects of the present manipulations would have been much stronger, but this, of course, is an empirical question. Another limitation is that our misinformation manipulations pertained to plausible details that had been either present or absent in the scenes. Thus, the question arises of what would have happened had confederates suggested or denied low-expectancy or even highly implausible memory details. Still another limitation was that individual free recall was obtained relatively shortly after collaborative recall and so one wonders whether the memory-undermining effects would have been weaker or stronger after a longer time delay. All these issues warrant further research, particularly with regard to the memory-undermining power of misinformation that takes the form of denying true details or events.

\section{Note}

1 When $t$-tests were conducted separately for the add and the deny condition, we found no significant differences in GCS scores between those who had accepted the misinformation and those who had not. This is probably due to a statistical power problem. Most importantly, there is no theoretical rationale for running separate $t$-tests.

\section{References}

Conte, J. R. (1999). Memory, research, and the law. In L. M. Williams, \& V. L. Banyard (Eds.), Trauma E memory (pp. 77-92). London: Sage.

Christianson, S. A., \& Merckelbach, H. L. G. J. (2004). Crime-related amnesia as a form of deception. In P. A. Granhag, \& L. A. Strömwall (Eds.), The detection of deception in forensic contexts (pp. 195-225). Cambridge, UK: Cambridge University Press.

Gabbert, F., Memon, A., Allan, K., \& Wright, D. B. (2004). Say it to my face: Examining the effects of socially encountered misinformation. Legal and Criminological Psychology, 9, 215-227.

Gabbert, F., Memon, A., \& Wright, D. B. (2006). Memory conformity: Disentangling the steps towards influence during a discussion. Psychological Bulletin $\mathcal{E}$ Review, 13, 480-485.

Gabbert, F., Memon, A., \& Wright, D. B. (2007). I saw it for longer than you: The relationship between perceived encoding duration and memory conformity. Acta Psychologica, 124, 319-331.

Gudjonsson, G. H. (1989). Compliance in an interrogation situation: A new scale. Personality and Individual Differences, 10, 535-540.

Gudjonsson, G. H. (2003). The psychology of interrogation and confessions: A handbook. New York: Wiley.

Gudjonsson, G. H., Sigurdsson, J. F., Bragason, O. O., Einarsson, E., \& Valdimarsdottir, E. B. (2004). Compliance and personality: The vulnerability of the unstable introvert. European fournal of Personality, 18, 435-443.

Henkel, L. A., \& Coffman, K. J. (2004). Memory distortions in coerced false confessions: A source monitoring framework analysis. Applied Cognitive Psychology, 18, 567-588.

Horselenberg, R., Merckelbach, H., Smeets, T., Franssens, D., Peters, G. J. Y., \& Zeles, G. (2006). False confessions in the lab: Do plausibility and consequences matter. Psychology, Crime E Law, 12, 61-75.

Hyman, I. E., Husband, T. H., \& Billings, F. J. (1995). False memories of childhood experiences. Applied Cognitive Psychology, 9, 181-197.

Loftus, E. F., Levidow, B., \& Duensing, S. (1992). Who remembers best? Individual differences in memory for events that occurred in a science museum. Applied Cognitive Psychology, 6, 93-107.

Loftus, E. F., \& Pickrell, J. E. (1995). The formation of false memories. Psychiatric Annals, 25, 720-725.

Paterson, H. M., \& Kemp, R. I. (2005). Co-witness talk: A survey of eyewitness discussions. Psychology, Crime E Law, 12, 181-191.

Roediger, H. L., Meade, M. L., \& Bergman, E. T. (2001). Social contagion of memory. Psychonomic Bulletin $\mathcal{E}$ Review, 8, 365-371.

Schwartz, B. L., Fisher, R. P., \& Hebert, K. S. (1998). The relation of output order and commission errors in free recall and eyewitness accounts. Memory, 6, 257-275. 
Sigurdsson, J. F., \& Gudjonsson, G. H. (1996). The psychological characteristics of false confessors: A study among Icelandic prison inmates and juvenile offenders. Personality and Individual Differences, 20, 321-329.

Wagenaar, W. A., \& Crombag, H. F. (2005). The popular police man and other cases: Psychological perspectives on legal evidence. Amsterdam: Amsterdam University Press.

Wright, D. B., Loftus, E. F., \& Hall, M. (2001). Now you see it; now you don't: Inhibiting recall and recognition of scenes. Applied Cognitive Psychology, 15, 471-482.

Wright, D. B., Mathews, S. A., \& Skagerberg, E. M. (2005). Social cognition memory: The effect of other people's responses for previously seen and unseen items. Fournal of Experimental Psychology: General, 11, $200-209$. 